Saudi Journal of Medicine

Abbreviated Key Title: Saudi J Med ISSN 2518-3389 (Print) |ISSN 2518-3397 (Online) Scholars Middle East Publishers, Dubai, United Arab Emirates

Journal homepage: https://saudijournals.com/sjm

Original Research Article

\title{
Clinical Correlation between Preoperative Serum Albumin and Postoperative Outcome in Major Gastrointestinal Surgeries
}

Dr. Arun $\mathrm{P}^{1^{*}}$, Dr. B Vikraman², Dr. Harikrishnan C $\mathrm{P}^{3}$, Dr. Jacob Antony Chakiath ${ }^{4}$, Dr. Greeshma Perumbilavil ${ }^{5}$, Dr. Tintumole C Tenny ${ }^{6}$

${ }^{1}$ Junior Resident, Department of Surgery, Mission Medical College \& Research Institute, Thrissur, Kerala 680005, India

${ }^{2}$ Professor, Department of general surgery, Jubilee Mission Medical College \& Research Institute, P. O, Jubilee Mission Rd, East Fort, Thrissur, Kerala 680005 , India

${ }^{3}$ Assistant Professor, Department of Surgery, Jubilee Mission Medical College \& Research Institute, P. O, Jubilee Mission Rd, East Fort, Thrissur, Kerala 680005, India

${ }^{4}$ Junior Resident, Department of Surgery, Jubilee Mission Medical College \& Research Institute, P. O, Jubilee Mission Rd, East Fort, Thrissur, Kerala 680005 , India

${ }^{5}$ Junior Resident, Department of Pathology, Government Medical College, Thrissur, Kerala 680005, India

${ }^{6}$ Junior Resident, Department Of Pharmacology, Government Medical College, Thrissur, Kerala 680005, India

DOI: $10.36348 / \mathrm{sjm} .2020 . \mathrm{v} 05 \mathrm{i} 03.003$

| Received: 16.02.2020 | Accepted: 01.03.2020 | Published: 06.03.2020

*Corresponding author: Dr. Arun $\mathrm{P}$

\section{Abstract}

Background: Albumin is a family of globular proteins, the most common of which are the serum albumins. All the proteins of the albumin family are water-soluble, moderately soluble in concentrated salt solutions, and experience heat denaturation. Albumins are commonly found in blood plasma and differ from other blood proteins in that they are not glycosylated. Substances containing albumins, such as egg white, are called albuminoids. It contributes to the oncotic pressure of plasma and to maintaining the distribution of extracellular fluid between the vascular and extravascular compartments. Hypoalbuminemia is associated with poor tissue healing, decreased collagen synthesis in the surgical wounds or at anastomotic sites [1], and also plays a role in the impairment of immune responses, such as macrophage activation and granuloma formation. Although it is well established that hypoalbuminemia, as a marker of malnutrition and disease, is associated with greater risk of adverse surgical outcome, previous studies have been based on relatively small samples and selected types of operations and have failed to adequately separate the predictive ability of albumin level from other risk factors. Aim of study: To determine whether preoperative serum albumin level can be used as an independent predictor of post-operative morbidity and mortality. Methods: This is a prospective comparison study conducted in general surgery department, Jubilee Mission Medical College. The source of the data will be all patients who undergo gastrointestinal surgery with resection and anastomosis in the Department of General Surgery, Jubilee Mission Medical College, Thrissur from December 2017 to May 2019. Patients are investigated preoperatively for liver function test, renal function test, thyroid function test and urine- protein creatinine ratio (obtained from urine microscopy) to rule out secondary causes of hypoalbuminemia and are classified into two groups:- normal albumin level and hypoalbuminemia. Patients with normal serum albumin level are compared with patients of low serum albumin for length of hospital stay, resumption of oral diet, surgical site infection and mortality. Results and Discussion: The preoperative albumin levels ranged from 2.1 to $3.4 \mathrm{~g} / \mathrm{dl}$ with a mean value of $3.03 \mathrm{~g} / \mathrm{dl}$. In most other similar studies [1-4], a similar cut off normal range ( 3 or $3.5 \mathrm{~g} / \mathrm{dl}$ ) was assigned and patients were grouped into two based on this. To explore the possibility of using serum albumin as a simple and low-cost prognostic tool to predict the risk of adverse surgical outcomes, we used different statistical methods. Mann-Whitney U test has been performed to find out the significant role of albumin levels for length of hospital stay (Median 10.5 days and 8 days) and delay in resumption of diet (Median 5days and 3days) among two groups and it showed that there was statistically significant association with albumin levels between two groups in length of stay $(\mathrm{p}=0.021)$ if we classify the length of hospital stay as less than 10days and more than 10days. It is statistically significant in resumption of $\operatorname{diet}(\mathrm{p}<0.001)$. There was a significant relationship found between the occurrence of surgical site infection and albumin levels. Where it was also found that those with low serum albumin had increased rates of complications (60\%) against those with normal serum albumin levels $32.5 \% .15 \%$ mortality cases were reported; of which $22.5 \%$ falls in low serum albumin level group where as $7.5 \%$ in normal albumin level group. Conclusion: In view of these results, we conclude that preoperative albumin is a good prognostic indicator for predicting the outcome of surgery. It is a cheap and easily applicable test. By estimating albumin levels in surgical patients before surgery and adequately correcting lower levels where necessary, post-operative morbidity could be reduced in these patients.

Keywords: Hypoalbuminemia, gastrointestinal surgery, postoperative morbidity, mortality.

Copyright @ 2020: This is an open-access article distributed under the terms of the Creative Commons Attribution license which permits unrestricted use, distribution, and reproduction in any medium for non-commercial use (NonCommercial, or CC-BY-NC) provided the original author and source are credited. 


\section{BACKGROUND}

Approximately one-third to one-half of hospitalized patients are malnourished at the time of admission [5], and this nutritional status can not only adversely affect a patient's clinical condition, but adversely affect their surgical outcomes as well. There are several tools to assess patient's nutritional status. Among these, serum albumin is a good and simple predictor of surgical risk and has a close correlation with the degree of malnutrition [6]. Hypoalbuminemia is associated with poor tissue healing, decreased collagen synthesis in the surgical wounds or at anastomotic sites [1], and also plays a role in the impairment of immune responses, such as macrophage activation and granuloma formation [7]. Hence, in hypoalbuminemic patients, wound infection, remote infections such as pneumonia, and anastomotic leaks are seen commonly. Several studies have been conducted to study association between hypoalbuminemia and surgical outcomes, particularly in cardiac and gastrointestinal surgery. In patients undergoing cardiac surgery, those who had lower serum albumin levels showed a trend toward having higher postoperative mortality and morbidity rates than did patients with normal serum albumin levels, while controlling for other risk factors [8]. Following gastrointestinal surgery, hypoalbuminemia has been proved to be a predictor of delayed recovery of bowel function and is strongly associated with postoperative complications after right hemicolectomy for right-sided colon cancer [6] or following other major gastrointestinal surgery [9]. In the case of rectal cancer surgery however, the effects of hypoalbuminemia on post-operative complications are still unclear $[2,10]$.

\section{AIMS \& OBJECTIVES}

Although it is well established that hypoalbuminemia, as a marker of malnutrition and disease, is associated with greater risk of adverse surgical outcome, previous studies have been based on relatively small samples and selected types of operations and have failed to adequately separate the predictive ability of albumin level from other risk factors [11]. To determine whether pre-operative serum albumin level can be used as an independent predictor of post-operative morbidity and mortality. To explore the possibility of using serum albumin as a simple and low-cost prognostic tool to predict the risk of adverse surgical outcomes like length of hospital stay, delay in resumption of oral diet, surgical site infections and mortality.

\section{MATERIALS AND METHODS}

A Prospective comparison study was planned in the Department of General Surgery, Jubilee Mission Medical College, Thrissur from December 2017 to May 2019. The source of the data were patients who underwent gastrointestinal surgery with resection and anastomosis during December 2017 to May 2019. (One year and 6 months) Patients above 18 years of age and patients undergoing major gastrointestinal surgeries with resection anastomosis were included in the study. Pregnant women, patients below 18 years of age and patients with cirrhosis liver and chronic kidney disease were excluded. Based on mean and standard deviation observed in an earlier publication with $95 \%$ confidence level and $90 \%$ power, Minimum sample size comes to 40 in both groups.

\section{METHODS OF DATA COLLECTION}

This is a prospective comparison study conducted in general surgery department, Jubilee Mission Medical College. The source of the data will be all patients who undergo gastrointestinal surgery with resection and anastomosis in the Department of General Surgery, Jubilee Mission Medical College, Thrissur from December 2017 to May 2019. Patients are investigated preoperatively for liver function test, renal function test, thyroid function test and urine- protein creatinine ratio to rule out secondary causes of hypoalbuminemia and are classified into two groups:normal albumin level and hypoalbuminemia. Patients with normal serum albumin level are compared with patients of low serum albumin for length of hospital stay, resumption of oral diet, surgical site infection and mortality and is followed up for a period of one month from the date of admission.

\section{Statistical Tests Used}

This prospective comparison study has been conducted by using case and control groups on the basis of pre-operative serum albumin levels. Patients with low pre-operative serum albumin levels $(<3.5 \mathrm{mg} / \mathrm{dl})$ have been taken as Case group and with normal preoperative serum albumin levels $(>=3.5 \mathrm{mg} / \mathrm{dl})$ have been taken as Control group. Results on continuous measurements are presented on Mean \pm SD, Median and inter-quartile range. Results on categorical measurements are presented in Number and percentage and represented in tables and figures wherever necessary. Significance is assessed at $5 \%$ level of significance. The collected data were coded and entered into the IBM SSPS Statistics, Version 20.0, a statistical package software program. Univariate analysis (chisquare/Fisher's exact tests) were carried out to determine the association of pre-operative serum albumin levels with surgical outcomes (morbidity and mortality) between the case and control groups. The relative risk of low serum albumin level included in the univariate analysis were estimated by odds ratio (OR) and the $95 \%$ confidence interval (CI) calculated. MannWhitney $U$ test has been performed to find out the significant role of pre-operative serum albumin levels for length of hospital stay and delay in resumption of diet among two groups. Comparison with other studies also carried out and showed as numbers and percentages in tables. 
Table-1: Demonstrates the mean and standard deviation of age of patients, median length of hospital stay, median resumption of diet, percentage of mortality, surgical site infection and complication in both groups

\begin{tabular}{|r|r|r|r|}
\hline & $\begin{array}{r}\text { Pre.op. Albumin } \\
\mathbf{3 . 5}(\mathbf{N = 4 0})\end{array}$ & $\begin{array}{r}\text { Pre.op. Albumin } \\
\mathbf{> = 3 . 5}(\mathbf{N = 4 0})\end{array}$ & p value \\
\hline Age (Mean Years) & $59.2 \pm 13.104$ & $59.63 \pm 12.919$ & \\
\hline LOHS (Median) & $10.50 \mathrm{IQR}(7-12.75)$ & $8 \mathrm{IQR}(7-10.75)$ & 0.089 \\
\hline ROD (Median) & $5 \mathrm{IQR}(4-5)$ & $3 \mathrm{IQR}(2-3)$ & $<0.001$ \\
\hline Mortality & $9(22.5 \%)$ & $3(7.5 \%)$ & 0.115 \\
\hline SSI & $24(60 \%)$ & $9(22.5 \%)$ & 0.001 \\
\hline Complications & $23(57.5 \%)$ & $13(32.5 \%)$ & 0.025 \\
\hline
\end{tabular}

The age of the patients included in the study ranged from 21 years to 79 years with a mean age of 59 years in both groups. Pre-operative albumin was measured in all patients and ranged from $2 \mathrm{~g} / \mathrm{dl}$ to 4.6 $\mathrm{g} / \mathrm{dl}$. Length of hospital stay: This was considered as the time from admission to discharge from hospital, and had a range of 7 to 12 in hypoalbumin patients and 7 to 10 in normal albumin patients with a median of 10.50 and 8 in each groups respectively. Resumption of diet: This was considered as the time from the end of procedure to the time patient resumed oral soft diet. Median of resumption of diet in normal albumin patients was 3 days and in hypoalbumin patients was 5 days. Mortality was $22.5 \%$ in hypoalbumin patients and $7.5 \%$ in normal albumin patients. Superficial surgical site infection was present in $60 \%$ of patients with hypoalbuminemia compared to $22.5 \%$ patients with normal albumin. Complications were seen in $57.5 \%$ of hypoalbumin patients compared to 32.5 in normal albumin patients. Mean length of hospital stay in hypoalbumin patients was found to be 10.8 days with a standard deviation of 4.245 and that of normal albumin patients was found to be 9.03 days with a standard deviation of 3.765. Mean for the resumption of oral diet in hypoalbumin patients was 4.83 days with a standard deviation of 1.200 and that of normal albumin patient was 2.71 days with a standard deviation of 0.694 . Mann-Whitney $U$ test has been performed to find out the significant role of albumin levels for length of hospital stay and delay in resumption of diet among two groups and it showed that it has no statistically significant role in length of stay $(\mathrm{p}=0.089)$ but it is statistically significant in resumption of diet $(p<0.001)$ as illustrated in Table-2.

Table-2

\begin{tabular}{|c|c|c|c|c|}
\hline \multicolumn{5}{|c|}{ Mann-Whitney Test } \\
\hline \multicolumn{5}{|r|}{ Ranks } \\
\hline & Group & $\mathrm{N}$ & Mean Rank & Sum of Ranks \\
\hline \multirow[t]{3}{*}{ Length of stay (days) } & Hypo albumin & 40 & 44.90 & 1796.00 \\
\hline & Normal albumin & 40 & 36.10 & 1444.00 \\
\hline & Total & 80 & & \\
\hline \multirow[t]{3}{*}{ Resumption of diet (day) } & Hypo albumin & 35 & 53.99 & 1889.50 \\
\hline & Normal albumin & 38 & 21.36 & 811.50 \\
\hline & Total & 73 & & \\
\hline \multicolumn{5}{|c|}{$\begin{array}{r}\text { Test Statistics } \\
\end{array}$} \\
\hline & Length of stay (days) & Resumption of diet (day) & & \\
\hline Mann-Whitney U & 624.000 & 70.500 & & \\
\hline Wilcoxon W & 1444.000 & 811.500 & & \\
\hline $\mathrm{Z}$ & -1.701 & -6.733 & & \\
\hline Asymp. Sig. (2-tailed) & .089 & .000 & & \\
\hline \multicolumn{3}{|c|}{ a. Grouping Variable: group } & & \\
\hline
\end{tabular}

If the length of hospital stay is divided as less than 10 days and more than 10 days in hypo albumin and nomal albumin groups, we get a statistically significant result that hypo albuminemia is associated with prolonged hospital stay. In hypoalbumin patients, $50 \%$ were discharged within 10 days and $50 \%$ after 10 days. Where as in case of normal albumin patients, $75 \%$ were discharged within 10 days and only $25 \%$ patients stayed more than 10 days. Total percentage of patients discharged within 10 days were $62.5 \%$. On evaluating it was found that length of stay more than 10 days become significant with $\mathrm{P}$ value in case of hypoalbumin patients. Chi-square test has been performed to find out the association of albumin levels for Mortality rate between two groups and it showed that it is not statistically significant $(\mathrm{p}=0.115)$. Chi-square test has been performed to find out the association of albumin levels for complications between two groups and it showed that it is statistically significant $(\mathrm{p}=0.025)$ Table-3. 
Table-3

\begin{tabular}{|c|c|c|c|c|c|}
\hline \multicolumn{6}{|c|}{ Crosstab } \\
\hline & & & \multicolumn{2}{|c|}{ complication } & \multirow[t]{2}{*}{ Total } \\
\hline & & & yes & Nil & \\
\hline \multirow[t]{6}{*}{ group } & \multirow[t]{3}{*}{ Hypo.Albumin } & Count & 23 & 17 & 40 \\
\hline & & $\%$ within group & $57.5 \%$ & $42.5 \%$ & $100.0 \%$ \\
\hline & & $\%$ within complication & $63.9 \%$ & $38.6 \%$ & $50.0 \%$ \\
\hline & \multirow[t]{3}{*}{ Normal.albumin } & Count & 13 & 27 & 40 \\
\hline & & $\%$ within group & $32.5 \%$ & $67.5 \%$ & $100.0 \%$ \\
\hline & & $\%$ within complication & $36.1 \%$ & $61.4 \%$ & $50.0 \%$ \\
\hline \multirow{3}{*}{\multicolumn{2}{|c|}{ Total }} & Count & 36 & 44 & 80 \\
\hline & & $\%$ within group & $45.0 \%$ & $55.0 \%$ & $100.0 \%$ \\
\hline & & $\%$ within complication & $100.0 \%$ & $100.0 \%$ & $100.0 \%$ \\
\hline
\end{tabular}

\section{DISCUSSION}

A sample of 80 patients undergoing laparotomy with resection and anastomosis were taken to determine the correlation between preoperative albumin and postoperative parameters. Serum albumin is a marker of disease and malnutrition and hence can be predictive of operative outcome. In addition, it also possibly confers a direct protective effect through several biochemical mechanisms. It is a better prognostic indicator of nutritional status than anthropometric markers [1, 12]. This prospective comparison study has been conducted to determine whether pre-operative serum albumin level can be used as an independent predictor of post-operative morbidity and mortality. For this we had taken two groups of 40 each cases and controls whose pre-operative albumin levels were $<3.5 \mathrm{mg} / \mathrm{dl}$ and with normal albumin levels $>=3.5 \mathrm{mg} / \mathrm{dl}$ respectively. In our study, $57.5 \%$ were male and $42.5 \%$ were female in hypo-albumin group where as in control group, $70 \%$ were male and $30 \%$ were female. Most other similar studies also have a greater percentage of men to women [1, 3, 4]. Mean ages of case and control groups were 59.2 and 59.63 respectively. This was comparable to the age of 61 years in the study by Gibbs, Lohsiriwat and Badia Tahul $[1,9,3]$. The preoperative albumin levels ranged from 2.1 to $3.4 \mathrm{~g} / \mathrm{dl}$ with a mean value of $3.03 \mathrm{~g} / \mathrm{dl}$. In most other similar studies, a similar cut off normal range ( 3 or $3.5 \mathrm{~g} / \mathrm{dl}$ ) was assigned and patients were grouped into two based on this [[1-4]. To explore the possibility of using serum albumin as a simple and lowcost prognostic tool to predict the risk of adverse surgical outcomes, we used different statistical methods.

\section{Comparison with other studies}

While comparing with other studies Ramya et al., [13], 38.8\% with low serum albumin level has been discharged in 10 days; $50 \%$ of the same in our present study got discharged in 10 days. By considering the delay in resumption of diet, $86.8 \%$ of normal albumin level patients could resume their diet in 3 days compared to $21.9 \%$ in other study. But in case of low albumin levels, our study shows only $8.6 \%$ compared to $11.1 \%$ in other study. In the case of surgical site infections, $60 \%$ of the low albumin group of our study got infections against $50 \%$ of the same in other study. Regarding post-operative Complications, Lohsiriwat et al., [9] found that $29 \%$ of the low serum albumin group had complications against none among the normal albumin group but in our study $60 \%$ of low serum albumin level group had complications against $32.5 \%$ of normal albumin level group.

\section{Length of Stay and Resumption of Diet}

Mann-Whitney $U$ test has been performed to find out the significant role of albumin levels for length of hospital stay (Median 10.5 days and 8 days) and delay in resumption of diet (Median 5days and 3days) among two groups and is statistically significant in resumption of diet $(\mathrm{p}<0.001)$. If we classify the length of hospital stay into two categories that is less than 10 days in one group more than 10 days in another group, the $\mathrm{p}$ value obtained is 0.021 which makes it significant that hypoalbuminemia is associated with increased length of hospital stay as seen with similar studies $[9,4$, $14,13,15]$. While $86.8 \%$ of the control group could resume their diet in 3 days, only $8.6 \%$ of patients with low serum albumin levels could do the same. Study conducted by Lohsiriwat [4], also showed delayed resumption of diet in hypoalbumin patients.

\section{Mortality}

As study of the literature revealed a positive association of low preoperative levels of albumin with postoperative mortality as well [1, 2, 10, 3, 4, 16-19]. $15 \%$ mortality cases were reported; of which $22.5 \%$ falls in low serum albumin level group where as $7.5 \%$ in normal albumin level group $(\mathrm{p}=0.115$, Odds Ratio $3.581)$

\section{Surgical Site Infections}

$41.3 \%$ of the total patients were affected with surgical site infections. There was a significant relationship found between the occurrence of surgical site infection and albumin levels. While $60 \%$ of case group affected with site infections, only $22.5 \%$ falls in control group ( $\mathrm{p}=0.001$, Odds Ratio 5.167). Gibbs and colleagues reported an incidence of $7.8 \%$ for deep infections and $6.8 \%$ for superficial infections in patients with low preoperative albumin. Sakurai et al., [20] also 
found that the incidence of SSI post gastrointestinal perforator surgery was significantly higher $(59.1 \%)$ in the patients with serum Albumin levels of $3.4 \mathrm{mg} / \mathrm{dL}$ or less. Vo et al., [18] also found that preoperative albumin (OR 0.52, 95\% CI 0.36-0.76), was associated with organ/space infection following colorectal surgeries.

\section{Complications}

It was also found that those with low serum albumin had increased rates of complications (60\%) against those with normal serum albumin levels $(32.5 \%)$ ( $\mathrm{p}<0.014$, Odds Ratio 3.115). Gibbs [1] documented a $19.6 \%$ incidence in 30 day morbidity in patients with low serum albumin preoperatively. Kudsk [2] also reported the inverse relationship of preoperative albumin and complications. In another study [21], it was found that an albumin level below the discriminatory threshold of $3.2 \mathrm{~g} / \mathrm{dL}$ was a significant predictor of overall postoperative morbidity, infectious and noninfectious complications, and mortality (all $\mathrm{P}<$ 0.001).

\section{SUMMARY \& LIMITATIONS}

In our one and half year single institution prospective comparative study, we estimated preoperative serum albumin levels in 80 patients undergoing laparotomy with resection and anastomosis and the patients were divided equally into two groups hypoalbumin and normal albumin according to their preoperative serum albumin level with a mean level of $3.5 \mathrm{~g} / \mathrm{dl}$. The included patients ranged from 18-80 years (mean age: 59 years in both groups). The preoperative albumin levels ranged from $2.0 \mathrm{~g} / \mathrm{dl}$ to $4.6 \mathrm{~g} / \mathrm{dl}$ (mean: $3.5 \mathrm{~g} / \mathrm{dl}$ ). We found a statistically significant correlation in occurrence of surgical site infections, delay in resumption of diet, increased length of hospital stay, mortality and other postoperative complications in patients with lower preoperative serum albumin. There are some limitations of the study such as Small sample size, Short duration of the study (18 months), Emergency cases also included in the study and No provision for correction of preoperative albumin even if found low.

\section{CONCLUSION}

Low preoperative albumin level is associated with a significantly higher risk of surgical site infection. Also, low preoperative albumin levels are associated with a significantly higher risk of other complications postoperatively. There is significant correlation between preoperative serum albumin levels and resumption of diet after surgery, that is, patients with a lower albumin level before surgery took longer to regain bowel function post operatively. There is statistically significant correlation between preoperative serum albumin levels and length of hospital stay. In view of these results, we conclude that preoperative albumin is a good prognostic indicator for predicting the outcome of surgery. It is a cheap and easily applicable test. By estimating albumin levels in surgical patients before surgery and adequately correcting lower levels where necessary, post-operative morbidity could be reduced in these patients.

\section{REFERENCES}

1. Gibbs, J., Cull, W., Henderson, W., Daley, J., Hur, K., \& Khuri, S. F. (1999). Preoperative serum albumin level as a predictor of operative mortality and morbidity: results from the National VA Surgical Risk Study. Archives of surgery, 134(1), 36-42.

2. Kudsk, K. A., Tolley, E. A., DeWitt, R. C., Janu, P. G., Blackwell, A. P., Yeary, S., \& King, B. K. (2003). Preoperative albumin and surgical site identify surgical risk for major postoperative complications. Journal of Parenteral and Enteral Nutrition, 27(1), 1-9.

3. Badia-Tahull, M. B., Llop-Talaveron, J., FortCasamartina, E., Farran-Teixidor, L., RamonTorrel, J. M., \& Jódar-Masanés, R. (2009). Preoperative albumin as a predictor of outcome in gastrointestinal surgery. $e-S P E N$, the European $e$ Journal of Clinical Nutrition and Metabolism, 4(5), e248-e251.

4. Lohsiriwat, V., Lohsiriwat, D., Boonnuch, W., Chinswangwatanakul, V., Akaraviputh, T., \& Lert-Akayamanee, N. (2008). Pre-operative hypoalbuminemia is a major risk factor for postoperative complications following rectal cancer surgery. World journal of gastroenterology: WJG, 14(8), 1248-1251.

5. Kuzu, M. A., Terzioğlu, H., Genç, V., Erkek, A. B., Özban, M., Sonyürek, P., ... \& Torun, N. (2006). Preoperative nutritional risk assessment in predicting postoperative outcome in patients undergoing major surgery. World journal of surgery, 30(3), 378-390.

6. 2Fuhrman MP, Charney P, Mueller CM. Hepatic proteins and nutrition assessment. J Am Diet Assoc 2004; 104:1258-64.

7. Irvin, T. T., \& Hunt, T. K. (1974). Effect of malnutrition on colonic healing. Annals of surgery, 180(5), 765-772.

8. Rich, M. W., Keller, A. J., Schechtman, K. B., Marshall, W. G., \& Kouchoukos, N. T. (1989). Increased complications and prolonged hospital stay in elderly cardiac surgical patients with low serum albumin. American Journal of Cardiology, 63(11), 714-718.

9. Lohsiriwat, V., Chinswangwatanakul, V., Lohsiriwat, S., Akaraviputh, T., Boonnuch, W., Methasade, A., \& Lohsiriwat, D. (2007). Hypoalbuminemia is a predictor of delayed postoperative bowel function and poor surgical outcomes in right-sided colon cancer patients. Asia Pacific journal of clinical nutrition, 16(2):213217.

10. Alves, A., Panis, Y., Mathieu, P., Mantion, G., Kwiatkowski, F., \& Slim, K. (2005). Postoperative 
mortality and morbidity in French patients undergoing colorectal surgery: results of a prospective multicenter study. Archives of surgery, 140(3), 278-283.

11. Agarwal, N., Acevedo, F., Leighton, L. S., Cayten, C. G., \& Pitchumoni, C. S. (1988). Predictive ability of various nutritional variables for mortality in elderly people. The American journal of clinical nutrition, 48(5), 1173-1178.

12. Goldwasser, P., \& Feldman, J. (1997). Association of serum albumin and mortality risk. Journal of clinical epidemiology, 50(6), 693-703.

13. Truong, A., Hanna, M. H., Moghadamyeghaneh, Z., \& Stamos, M. J. (2016). Division of Colon and Rectal Surgery, Department of Surgery, University of California, Irvine Medical Center, Orange, CA 92868, United States. World Journal Gastrointest Surgery, 8(5):353-362.

14. Koertzen, M., Punjabi, P. P., \& Lockwood, G. G. (2013). Pre-operative serum albumin concentration as a predictor of mortality and morbidity following cardiac surgery. Perfusion, 28(5), 390-394.

15. Ionescu, D., Tibrea, C., \& Puia, C. (2013). Preoperative hypoalbuminemia in colorectal cancer patients undergoing elective surgery-a major risk factor for postoperative outcome. Chirurgia (Bucur), 108(6), 822-828.

16. Bhamidipati, C. M., LaPar, D. J., Mehta, G. S., Kern, J. A., Upchurch Jr, G. R., Kron, I. L., \& Ailawadi, G. (2011). Albumin is a better predictor of outcomes than body mass index following coronary artery bypass grafting. Surgery, 150(4), 626-634.

17. Hennessey, D. B., Burke, J. P., Ni-Dhonochu, T., Shields, C., Winter, D. C., \& Mealy, K. (2010). Preoperative hypoalbuminemia is an independent risk factor for the development of surgical site infection following gastrointestinal surgery: a multi-institutional study. Annals of surgery, 252(2), 325-329.

18. Ho, V. P., Stein, S. L., Trencheva, K., Barie, P. S., Milsom, J. W., Lee, S. W., \& Sonoda, T. (2011). Differing risk factors for incisional and organ/space surgical site infections following abdominal colorectal surgery. Diseases of the colon \& rectum, 54(7), 818-825.

19. Garg, T., Chen, L. Y., Kim, P. H., Zhao, P. T., Herr, H. W., \& Donat, S. M. (2014). Preoperative serum albumin is associated with mortality and complications after radical cystectomy. BJU international, 113(6), 918-923.

20. Sakurai, J. (2010). Correlation between the Preoperative Serum Level of Albumin and Development of SSI After Surgery for Digestive Tract Perforation. Nihon Fukubu Kyukyu Igakkai Zasshi. Journal of Abdominal Emergency Medicine, 30(1):1340-2242.

21. Lin, M. Y., Liu, W. Y., Tolan, A. M., Aboulian, A., Petrie, B. A., \& Stabile, B. E. (2011). Preoperative serum albumin but not prealbumin is an excellent predictor of postoperative complications and mortality in patients with gastrointestinal cancer. The American Surgeon, 77(10), 1286-1289. 